\title{
A Teoria da Relatividade em Portugal (1910-1940) ${ }^{\star}$
}

\author{
Augusto José dos Santos Fitas \\ Centro de Estudos de História e Filosofia da Ciência, Universidade de Évora, \\ Apartado 94, 7002-554 Évora, \\ afitas@uevora.pt
}

\section{Introdução}

No Portugal do período entre guerras a Teoria da Relatividade não passou despercebida e foi alvo de referência e de alguma reflexão, tendo sido tema de relatórios académicos, cursos universitários, comunicações a congressos e ainda de alguns, escassos, trabalhos de investigação mais ligados ao domínio das matemáticas. Em torno desta teoria expressaram-se ideias a favor e contra, tendo-se estabelecido algumas polémicas públicas.

Da análise dos diferentes materiais produzidos percebe-se que a resposta da comunidade universitária portuguesa se centrou, sobretudo, nos professores de Física Matemática e Astronomia, um grupo mais ligado à Matemática do que à Física. Até à década de trinta a relatividade parece não ter interessado cientificamente os físicos portugueses e, além do desinteresse, mantinham sobre ela um profundo cepticismo. Embora tenham sido os matemáticos, os primeiros a apresentar a nova teoria em programas de disciplinas universitárias e a desenvolver alguma, pouca, investigação em torno de aspectos matemáticos relacionados com a Relatividade Geral, também no seio deste grupo se assistiu à expressão pública de posições antirelativistas. É na viragem da década de vinte para trinta que os físicos vão interessar-se mais por esta teoria, o que se manifestará unicamente na realização de seminários e na sua inclusão nos programas de disciplinas ministrados no âmbito de cursos universitários.

\footnotetext{
* Texto de uma conferência com o mesmo título feita na 13aㅡ Conferência Nacional de Física realizada em Évora em Setembro de 2002. Este texto foi publicado numa versão reduzida na Gazeta de Física. Vol. 27, fasc. 2 (2004), p. 4-10.
} 
É na sua vertente filosófica, como teoria responsável quer pela alteração do quadro tradicional das noções de espaço e tempo quer pelo apoio dado às novas correntes de filosofia da ciência, nomeadamente no que diz respeito ao neopositivismo, que a intervenção sobre a Relatividade também se fará sentir na vida cultural portuguesa. Esta teoria será objecto de um maior número de títulos em revistas de índole cultural, como é o caso da Seara Nova, O Diabo e o Sol Nascente, quando comparado com o conjunto e intervenções de carácter estritamente científico. Em meados da década de trinta a bandeira relativista é uma das bandeiras culturais içadas no baluarte daqueles que, em nome do progresso, se opõem ao stato quo implantado em Portugal pela constituição de 1933. De tal modo esta vertente cultural é importante, que as polémicas, anti e pró relatividade, atrás aludidas, se travarão quase na íntegra nas páginas dos jornais acabados de mencionar.

\section{Os primeiros passos até à expedição à llha do Príncipe}

As equações da transformação de Lorentz-Fitzgerald, devidamente acompanhadas por uma discussão sobre o Princípio da Relatividade, aparecem escritas, pela primeira vez, em Portugal pela pena de um jovem licenciado em Matemática na Escola Politécnica do Porto, não com propósitos de explanação científica, mas como matéria propiciadora de reflexão filosófica. É seu autor Leonardo Coimbra e a matéria exposta constitui parte da dissertação apresentada ao concurso, em 1912, a assistente de Filosofia da, então muito recente, Faculdade de Letras da Universidade de Lisboa ${ }^{1}$. Neste trabalho a Relatividade restrita é discutida com base num artigo de Langevin ${ }^{2}$ aparecido no Bulletin de la Societé Française de Philosophie que é saudado cientificamente nos seguintes termos: «Langevin (...) numa tese notável e audaz, demonstra que o princípio da relatividade permanece, mudando 0 sentido das noções de espaço e tempo" (COIMBRA, 1983, 103). Leonardo Coimbra adoptou a formulação do cientista francês: a discussão desenvolvese em torno do princípio da relatividade e não de uma nova teoria; o princípio, não era então entendido como um postulado de uma nova teoria, mas como um enunciado decorrente da experiência negativa de pôr em evidência o

\footnotetext{
${ }^{1}$ COIMBRA, Leonardo, Criacionismo, in Sant'anna Dionísio (coord.), 1983, Obras de Leonardo Coimbra, vol.I, Porto, Lello \& Irmão-Editores.

2 LANGEVIN, Paul, 1912, Le temps, l'espace et la causalité dans la physique contemporaine, Bulletin de la Societé Française de Philosophie, 12, 1-46.
} 